\title{
Macromolecules and Enzymes: The Geneva Heritage from Kurt H. Meyer and Edmond $\mathrm{H}$. Fischer
}

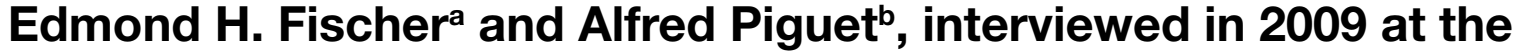 \\ Section de chimie et biochimie of the University of Geneva
}

\begin{abstract}
On the 26th May 2009, Edmond Fischer, winner with Ed Krebs of the Nobel prize in physiology or medicine in 1992, and his colleague at the time of his research activities at the Ecole de chimie of the University of Geneva, Alfred Piguet, met with Andreas Hauser, Claude Piguet and Howard Riezman of the Section de chimie et biochimie of the University of Geneva to talk about how they became scientists under the impetus of Kurt $\mathrm{H}$. Meyer and what became of them thereafter.
\end{abstract}

Keywords: $\alpha$-Amylase · Fischer, E.H. Nobel Laureate in 1992 · Meyer, K. H. · Phosphorylase ·

Phosphorylation · University of Geneva

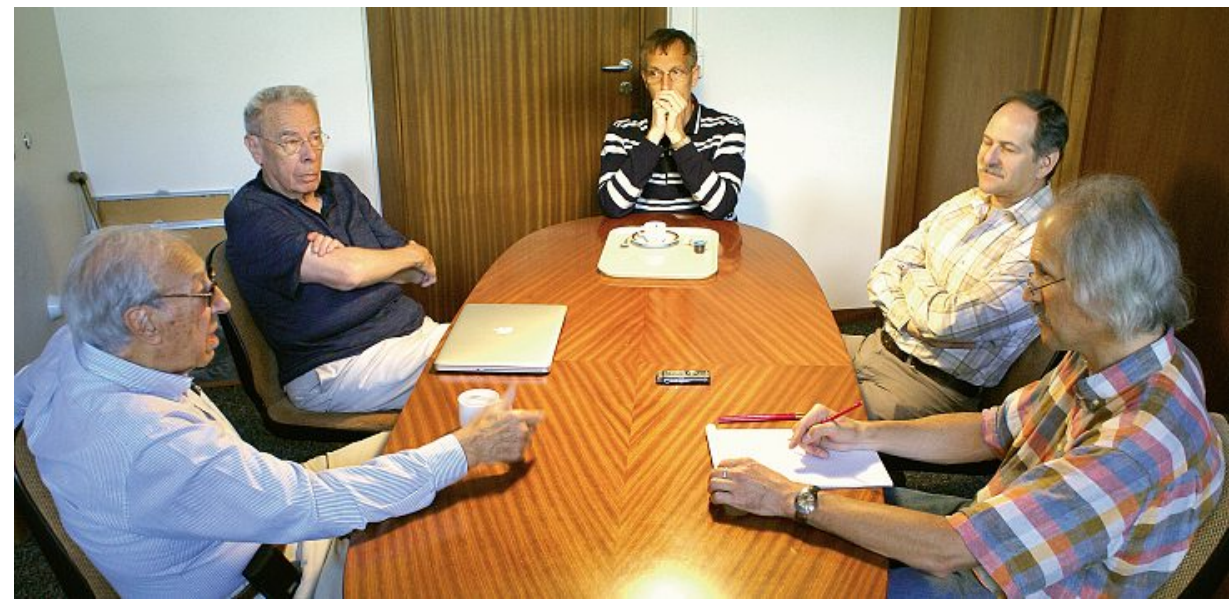

Edmond Fischer, Alfred Piguet, together with Andreas Hauser, Howard Riezman and Claude Piguet at the Science II building of the Faculty of Science of the University of Geneva (photo D. Perret, 2009).

Hosts: We are very pleased to welcome you both, Edmond Fischer and Alfred Piguet, on the occasion of the $450^{\text {th }}$ anniversary of the Academy and University of Geneva, to tell us about how you came to get involved in science in general and in biochemistry in particular almost 70 years

${ }^{*}$ Correspondence: Prof. A. Hauser, Président de Section

Section de chimie et biochimie

Université de Genève

30, quai Ernest-Ansermet

$\mathrm{CH}-1211$ Genève

Tel.: +4122 3796559

Fax: +4122 3796103

E-mail: andreas.hauser@unige.ch

aDepartment of Biochemistry

University of Washington

Seattle, WA, USA

${ }^{\mathrm{b}} \mathrm{CH}-1214$ Vernier ago. Also, to tell us about your personal experiences at the Ecole de chimie of the University of Geneva in your daily work in the group of Professor Kurt Meyer, and what became of you thereafter. So let's get started with you, Eddy: tell us how did you become interested in chemistry and biochemistry?

Edmond H. Fischer: Well, I became interested in science very early, when I was 14 or 15 , in the mid thirties. I had read a couple of books about microbe hunters, people like Robert Koch, who discovered the tuberculosis bacillus, about Semmelweis, who recognized the infectious nature of puerperal fever, and about Louis Pasteur, the French microbiologist for whom I had an immense admiration. I remember that the first time I went to Paris from Geneva, on an Easter vacation, the first thing I wanted to see was the Eiffel Tower, like anybody else, but then I went to see the tomb of Napoleon at the Palais des Invali- des, and then the tomb of Louis Pasteur at the Pasteur Institute. Pasteur's group had done extensive work on tuberculosis and because my father had tuberculosis like so many people in those days, and as there was no cure for that disease, I wanted to become a microbiologist, dreaming, of course, to find a cure for it. Unfortunately, my father, who was a heavy smoker, died of TB before I could even enter the field.

So, I wanted to become a microbiologist, and as the time came for me to enter the University of Geneva in 1939, I asked Prof. Fernand Chodat of the Department of Bacteriology how to best proceed. I'll always remember what he told me: "If you really want to become a good microbiologist, study chemistry first", so I enrolled at the Ecole de chimie and obtained my degree in chemistry. When it came time to choose a thesis project, I decided to work with Kurt Meyer, head of the department of organic chemistry and foremost expert on macromolecules. In those days, even top people like Paul Karrer refused to believe that molecules like the polysaccharides, starch or glycogen, had molecular weights in the millions. But Meyer insisted that this was the case and, together with Paul Mark, he finally convinced the scientific community with a paper published in 1928 , in which they presented X-ray diffraction results on a synthetic polymer. Kurt Meyer was primarily interested in the structure of natural polymers such as the polysaccharides. For this he needed enzymes in order to cut the molecules into manageable fragments. So he proposed to me to work on such an enzyme called $\alpha$-amylase, which cuts polysaccharides randomly. Kurt Meyer asked me to not only isolate but also to purify a sufficiently large quantity of $\alpha$ amylase, in order to prove that it was a protein and not a polysaccharide as had been 
proposed some time earlier by Willstätter and Waldschmidt-Leitz. Well, before actually embarking on my research work, I went to visit Professor Emile Briner, head of the department of physical chemistry, to tell him about my project. He looked at me quite unconvinced and said: "Enzymes, enzymes....do we know if they really exist?" Of course, we ourselves were quite convinced that they really did.

Alfred Piguet: In fact, one half of Meyer's group was fully occupied with analysing fragments of polysaccharides using the enzymes isolated and produced by the other half. My thesis subject was $\beta$-amylase, so I belonged to the same group as Eddy. I remember very well our tournaments of boules ferrées, usually on Thursday evening, the 'Polysaccharides' playing the 'Enzymes'. Both science and a simple game need teamwork and competition in order to achieve significant progress.

Hosts: Would it be fair to say that this work started biochemistry at the University of Geneva; did you see yourselves as biochemists?

E. Fischer: Well biochemistry was in its infancy in Europe at that time. Michaelis and Menten had just published their famous work on enzyme kinetics, and the publication of a new exciting series of books called 'Advances in enzymology' had just been initiated. My mother had sent me from the US, as a birthday present, the first two volumes of this series which I used for a course on enzymology I gave at the University of Geneva in 1950 as young privat-docent. So yes, we did see ourselves as biochemists.

Hosts: So in the late forties and early fifties, enzymes were the hot topic in biochemistry?

E. Fischer: Certainly, they were one of the hot topics. But work on mitochondria, the power house of the cell, was going on full blast. Then came the remarkable discovery by Watson and Crick of the structure of DNA which, with the work of the Pasteur group on bacterial genetics and other studies, triggered the incredible explosion in molecular biology and today's genetic engineering. And genomics was just round the corner, too.

Hosts: But one mustn't forget that enzymology provided the tools for this explosion.

E. Fischer: Yes, of course. Restriction enzymes provided Fred Sanger with the tools to sequence DNA, which became of huge importance. By the way, restric-

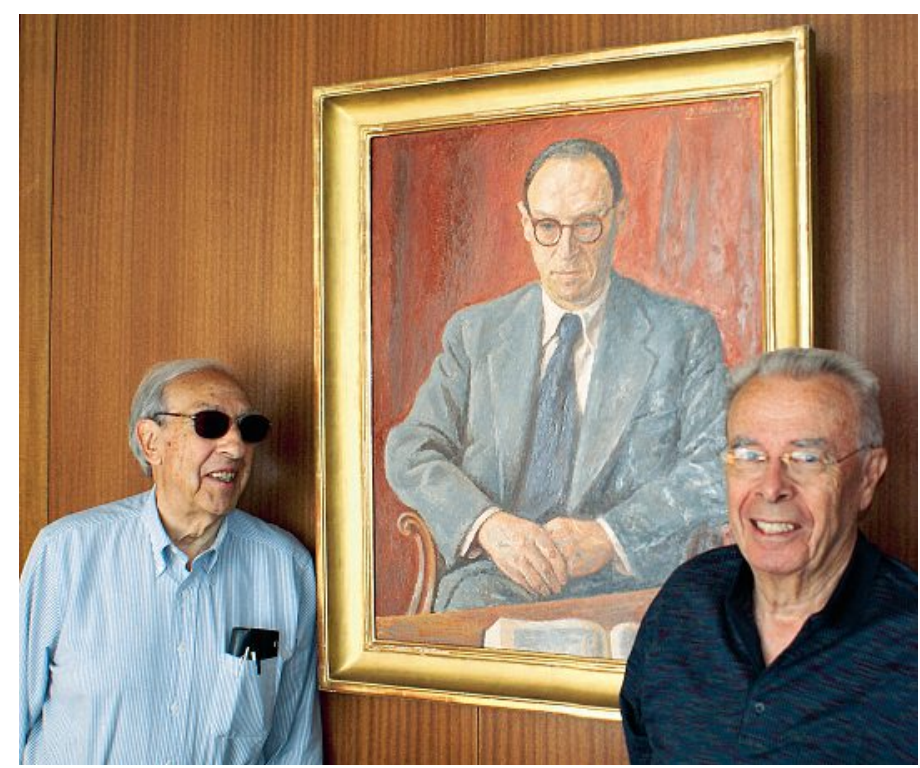

Edmond $\mathrm{H}$. Fischer and Alfred Piguet with the painting of Kurt H. Meyer by Robert Blanc at the Science II building of the Faculty of Science of the University of Geneva (photo D. Perret).

tion enzymes were actually discovered by Werner Arber in the late fifties while he was working at the University of Geneva, work that led him to receiving the Nobel Prize in medicine or physiology in 1978.

Hosts: How did Kurt Meyer influence you scientifically?

A. Piguet: Kurt Meyer had the aura of the Patron. We admired him. He created an extraordinary ambiance in his laboratory. Teamwork and team spirit were primordial. Everyone really worked very hard in the laboratory because progress depended upon the work of everybody in the group.

E. Fischer: Kurt Meyer led a very serious research group. He asked fundamental questions and expected rigorous scientific answers. The environment was very international for the time with a lot of visitors from all over the world. The experimental methods were rather crude and the apparatus were mostly home-built, like our treasured free-boundary electrophoresis. We would start off with 501 of some solution in order to end up with a few tens of milligrams of purified enzyme. We had no refrigerated centrifuge; we had to place our only ordinary centrifuge inside a cold room. But Kurt Meyer was very much attracted by novel methodology and instrumentation, and I believe he obtained something like 50000 Swiss francs of research money from the Stiftung auf dem Gebiete der Chemie, an enormous sum at the time. Some of it went towards the purchase of the first Beckman UV-Vis (DU) spectrophotometer, which he brought back personally after a visit to the US.

Hosts: For Kurt Meyer, enzymes were initially just a tool to cut his polymers, the latter being his chief interest. However, the enzymes became a field of much broader interest and finally of equal importance. Did Kurt Meyer realize this at the time?

E. Fischer: Well, of course. Kurt Meyer realized this but he was indeed mainly interested in macromolecules, and had he not died prematurely, I'm quite certain he would have shared the Nobel Prize in Chemistry with Staudinger in 1953. As you may know, there was a fierce competition between Meyer and Staudinger in the field of macromolecular chemistry, and Meyer was very much involved in one of those the scientific battles that were in vogue at the time.

Hosts: Well, finally your time at the University of Geneva came to an end. Alfred Piguet, what did you do after having obtained your PhD?

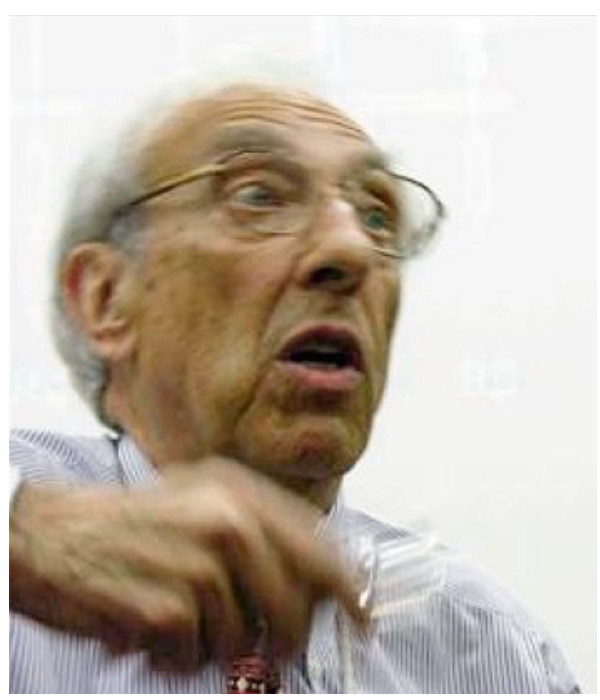

Edmond $\mathrm{H}$. Fischer during a lecture before the Chemical Society of Geneva in 2005 (photo D. Perret). 


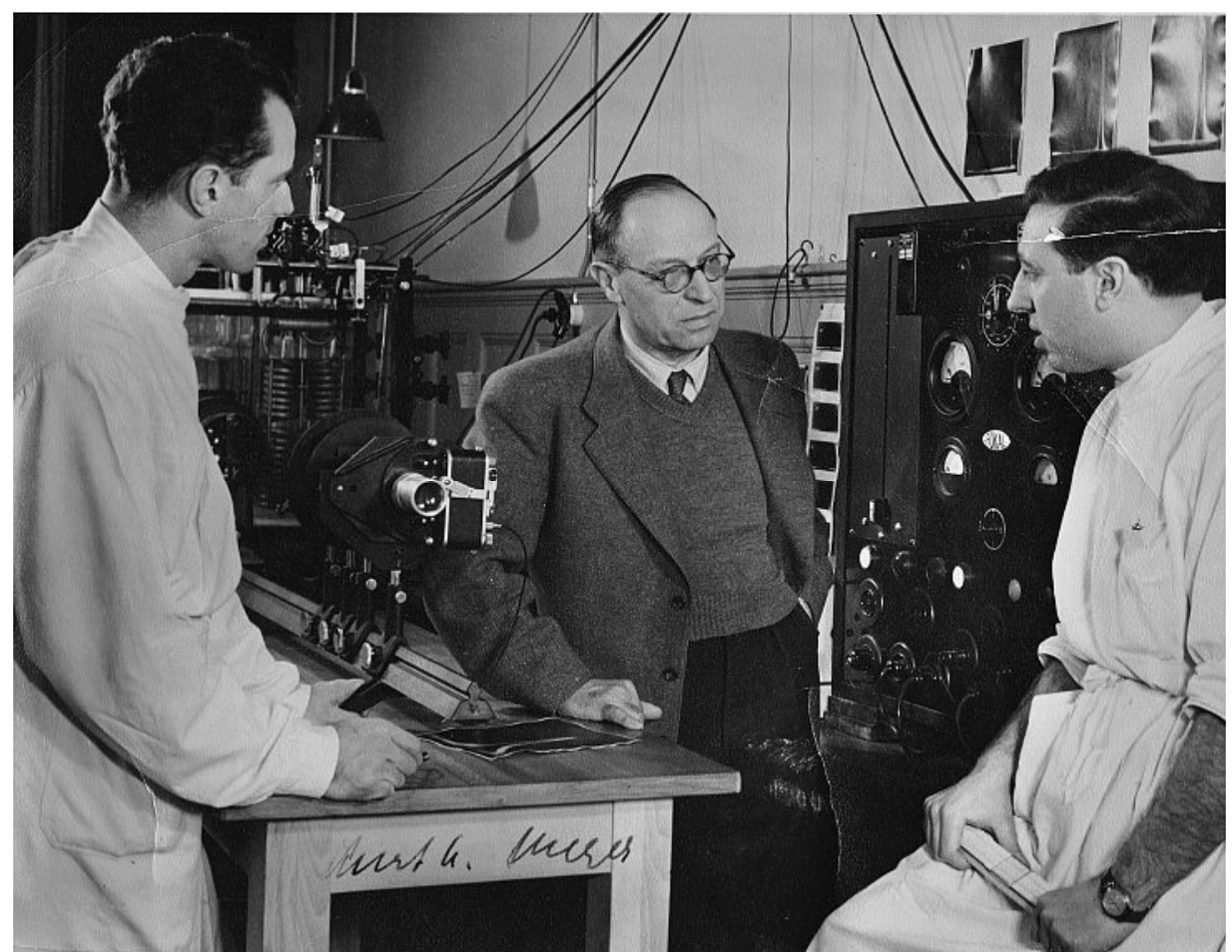

Roger Boissonnas, Kurt H. Meyer and Edmond H. Fischer (from left to right) in their laboratory at the School of chemistry on the Boulevard des Philosophes together with their highly treasured free-boundary electrophoresis apparatus (by courtesy of E. Fischer).

PURIFICATION ET CRISTALLISATION D' $\alpha$-AMYLASES

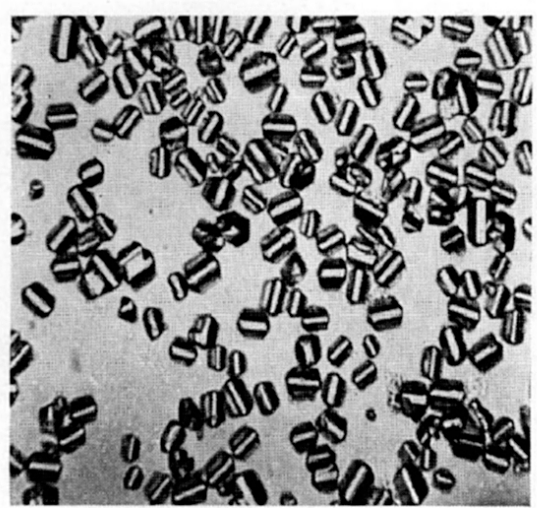

Fig 1. $(150 \times)$

Salive humaine

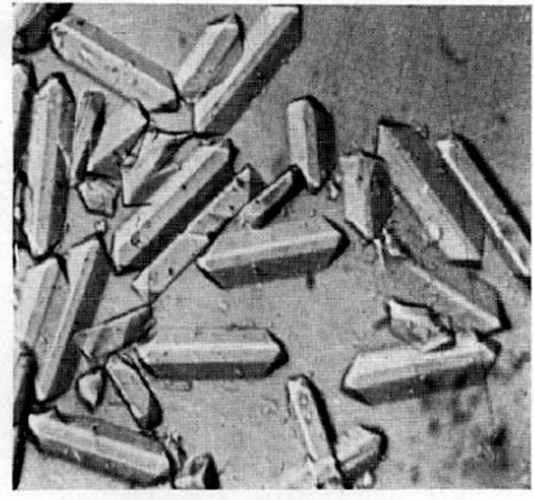

Fig. $3(165 \times)$

Pancréas de Porc

Some of the famous first crystals of the enzyme $\alpha$-amylase (by courtesy of E. Fischer).

A. Piguet: I had the enormous chance to be able to go and work with Woodward at Harvard in 1952 as a post-doc, where I was confronted with a top class environment of synthetic organic chemistry in the form of the total synthesis of steroids. I also saw my first infrared spectrometer and other important analytical tools. I had the impression that, in those days, Europe was 20 years behind the times. On my return to Geneva I worked for a while at Battelle in applied chemical research, before I decid- ed to completely re-orient my professional activities on the spur of the moment by accepting the position of director of the Portland cement factory in Geneva. Chance plays an important role in any career, but one has to see it when it comes along and be adventurous and grab it. I never regretted having seized this chance even though it meant partially leaving chemistry.

E. Fischer: Well, I always wanted to go to the US and Kurt Meyer's untimely death hurried things along. Then my visa was granted far more quickly than I expected and so, in 1953, I went to Caltech on a Swiss-Postdoctoral Fellowship, which Paul Karrer helped me get. But upon arriving in the US, I was first invited by Maria Fuld (another long-time K. H. Meyer collaborator) to give a seminar in Pittsburgh and then by Henry Lardy in Madison. To my surprise, in both instances, they offered me a job. On my arrival at Caltech I found a letter from Hans Neurath who invited me to come to the University of Washington in Seattle for the same purpose. I thought the Americans were crazy: they were offering me positions wherever I went whereas in Europe, jobs were one in a million. It had nothing to do with me: in the US, at that time, they were opening new medical schools right and left. So my wife and I decided to settle down in Seattle, which reminded us a lot of Geneva, with its lake and the mountains behind, and I have never regretted that decision. America was really the land of opportunities.

Hosts: Was there a key experiment which influenced your scientific work seminally.

E. Fischer: There was, of course, the crystallization of $\alpha$-amylase, which came out big in the literature and led to some important results. But that was just a simple crystallisation. The work on phosphorylase which I undertook in Seattle with Ed Krebs, who quickly became a life-long friend, was really much more important. But there was no single experiment that was more outstanding than others. Rather, every evening, we planned the experiments for the next day. Steady progress eventually paved the way to our discovery of reversible protein phosphorylation, which, by luck, turned out to be the most prevalent mechanism by which cellular processes are regulated. Prize.

Hosts: Work which led to the Nobel

E. Fischer: Yes, the Nobel Prize came as a surprise and it really was an awkward experience. Exhilarating, of course, as you can well imagine, but at the same time unsettling. OK - if you win a gold medal in the Olympic games, you know darn well why you won it: you trained like crazy for several years for that single purpose, you competed with a bunch of guys and beat them all. So you knew that you really deserved it. Not so with the Nobel Prize. You did your work because it was what you always wanted to do, and nothing would have been done differently had there been no reward at the end of the line. So the Prize catches you by surprise and you ask yourself: "Why were we selected?" among 


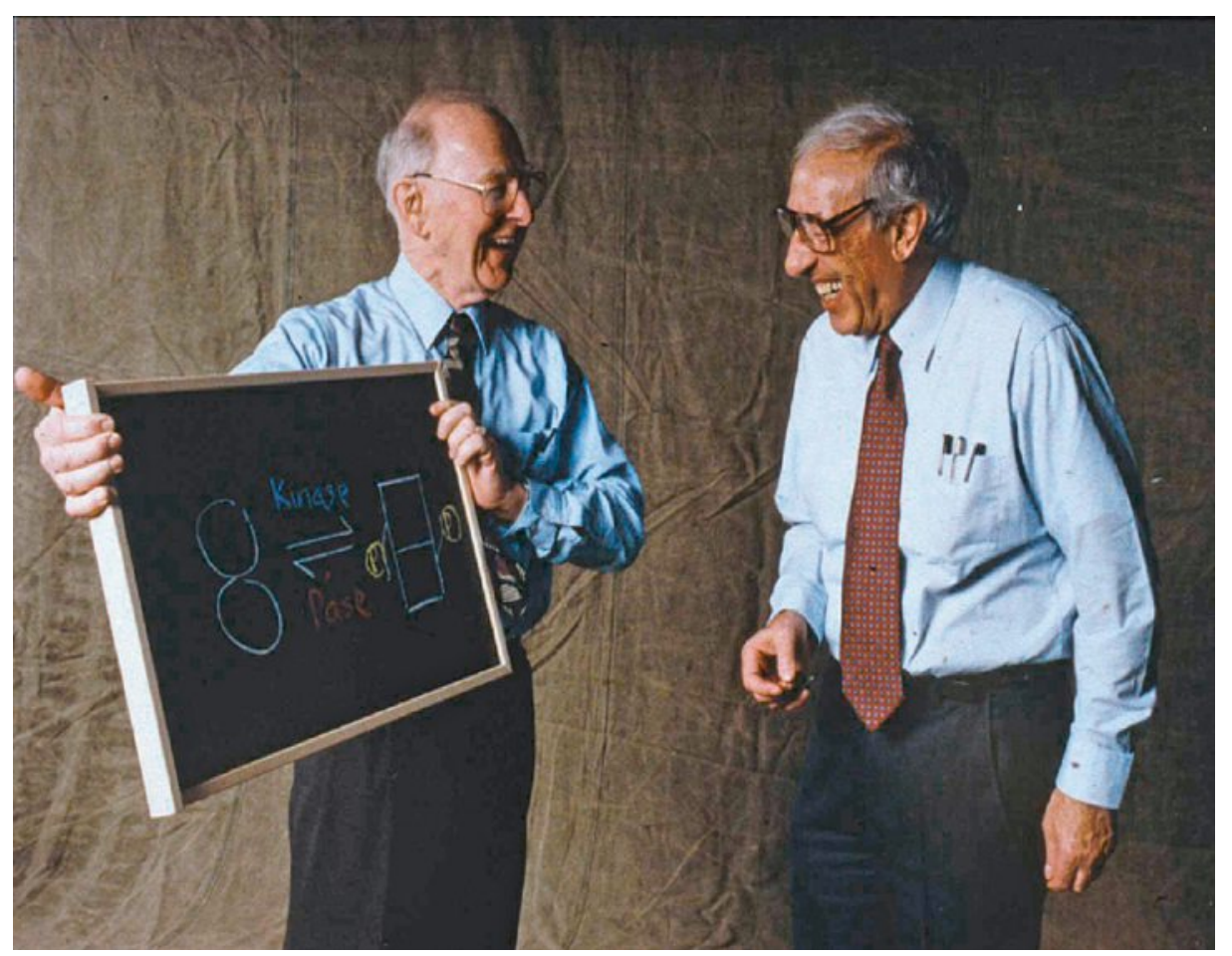

Edwin G. Krebs and Edmond H. Fischer at the Nobel Prize ceremony in 1992 explaining how phosphorylation works (by courtesy of E. Fischer).

so many people doing beautiful work in so many different areas. Initially, Ed and I worked side-by-side, alone at the bench. But as work progressed, we began to add graduate students and then post-docs and technicians to our group. We were blessed with having, over the years, a superb group of collaborators without whom we would never had been able to accomplish all that we did. So, if we were singled out for opening the field, for getting the ball rolling, the award we received has to be seen as recognition of their collective contributions. It was not a 'hole in one'.

Hosts: What would be your advice to young students today wanting to do a $\mathrm{PhD}$ ?

E. Fischer: Well, my advice to young students would be to choose a significant problem, one that fascinates you, that excites your curiosity. Don't work in an area that is too crowded, with big names attached to it: the competition might be too severe. Choose an area which is in its infancy, and don't get discouraged by failures. In fact, experimental results which are contrary to one's predictions are often the most interesting. They tell us that something different, something novel, is going on. A scientist, like an artist, has to rely a lot on his intuition and his imagination.

Hosts: Well, this is exactly what you did yourself and one can't argue with success. Eddy Fischer, Alfred Piguet, we thank you very much for a most enjoyable conversation.

Received: September 23, 2009 